\title{
Potential uses of health promotion competencies
}

\author{
Trevor Shilton, Peter Howat, Ray James, Cheryl Hutchins and Linda Burke
}

\section{Introduction}

In recent years, a number of projects internationally have defined and clarified competencies deemed desirable for working in health promotion. These developments first took place in the US, and more recently in Australia, New Zealand, Canada, Israel and Europe.

The earliest developments took place in the late 1970s in the US to define the role of entry level health educators. This work led to the latest US project completed in 2004, to further define and verify the role of advanced level health educators. ${ }^{1,2}$ In Canada, serious activity in this area was first documented in 2000 and a draft of competencies for health promotion practitioners was developed in 2006. ${ }^{3}$ Similar work was undertaken in a few other countries such as New Zealand ${ }^{4}$ and Israel. ${ }^{5}$ Work on the development of core competencies for health promotion professionals in European countries has only recently been undertaken by member states of the European Union and Council of Europe. ${ }^{6}$

In Australia, national projects to identify health promotion competencies were conducted in the early 1990s by the Western Australian Centre for Health Promotion Research at Curtin University (WACHPR), with the National Heart Foundation of Australia (Western Australian Division) and the Health Department of Western Australia, under the auspices of the Australian Association of Health Promotion Professionals (now the Australian Health Promotion Association, AHPA). These projects were developed in a collaborative way through consultation with the health promotion workforce. ${ }^{7}$ The Australian Health Promotion Competencies were revised in 2001 under the auspices of AHPA and the National Health Promotion Workforce Development Task Group, a committee of the National Public Health Partnership Group. ${ }^{8} \mathrm{~A}$ recommendation of the 2001 study was that the competencies should be reviewed and updated at least in a five year cycle. Subsequently, a further revision was conducted by AHPA, the Public Health Association of Australia Health Promotion Special Interest Group (PHAA HPSIG), and the International Union for Health Promotion and Education (IUHPE) SW Pacific Regional Committee in $2005 .^{9}$

The process used for the above studies was subsequently applied to a similar project in Israel in 2003 and the Health Promotion Competencies were also a major focus in the International Union for Health Promotion and Education (IUHPE) 2004 Melbourne World Conference Workforce Development Stream. Feedback from conference participants indicated strong international support for the development of a set of core competencies for the health promotion workforce. $^{10}$

\section{Abstract}

Projects in Australia and internationally over the past two decades have sought to define and clarify competencies required to work in health promotion. It is now apparent that such competencies are very useful to health promotion practice. However, to date little attempt has been made to describe those uses.

More than 200 health promotion practitioners throughout Australia were engaged in workshops to explore and define potential uses of health promotion competencies. The suggestions from these 10 workshops are summarised in eight categories of uses.

Agreed health promotion competencies have potential to impact on recruitment, training, employment policy and health promotion practice.

Key words: Health promotion competencies, workforce development, training, uses

There has been significant recent international interest and progress in developing competencies required to work in the health promotion field. This article moves the discussion on to consideration of the potential uses of these competencies and illustrates their relevance. 
A project management group representing these key organisations was formed consisting of Trevor Shilton, Peter Howat, Ray James, Cheryl Hutchins and Linda Burke. This group attempted to ensure that the Australian health promotion competencies reflected the views of those who work in the field, as well as experts in the area. In addition, the management group conducted research to identify perceptions regarding the potential uses of health promotion competencies. This discussion of potential uses for health promotion competencies draws on a series of workshops conducted across Australia throughout 2006.

\section{Method}

After analysis of data from a sample of 400 health promotion practitioners and leaders in November 2005, ${ }^{9}$ the authors conducted workshops throughout 2006 to investigate participants' perceptions of the uses for which the collaboratively developed competencies could be used. Ten workshops were held in all States and Territories of Australia. Each workshop followed a similar program which included:

- Discussion of the method, results and implications of research to revise health promotion competencies in Australia in 2005.

- Comparison of 2005 results to similar research in 2001.

- Discussion in small groups to:

discuss, then list potential practical uses for collaboratively developed health promotion competencies in Australia. The main comments made by the participants about the potential uses were recorded by one person in each group. This information was then manually coded and categorised. Data were then analysed according to the recommendations of Miles and Huberman (1994), ${ }^{11}$ where recurrent patterns are noted and clustered to form categories of data in order to generalise meaning. Initially, coding was carried out as a process of open coding generating eight separate categories. These were then used as sub-categories for the process of axial coding. These coding categories were then audited by two other researchers in order to ascertain whether the interpretations made by the researcher accorded with those of the participants. Results were then collated and presented thematically.

The potential uses of health promotion competencies listed below are derived from discussions in the workshops as well as from previously published work of the research group. ${ }^{8,12}$ In June 2007, the results from the Australian workshops were presented at the IUHPE World Conference on Health Promotion and Health Education in Vancouver, Canada. The uses of competencies identified in the Australian process were well received in this global forum. ${ }^{9}$

\section{Potential uses of health promotion competencies}

The uses of health promotion competencies are summarised within eight categories.

\section{Clarification of definitions of health promotion}

There was general agreement that health promotion competencies should be congruent with recognised definitions of health promotion. Lists of competencies should be informed by appropriate definitions of health promotion and health promotion practice as described in contemporary literature. In turn, competencies that are developed in consultation with the workforce can add clarification to definitions of health promotion and contribute to the evolution of such definitions to ensure they reflect contemporary practice. The competencies can provide a common language and vocabulary for the profession and help to differentiate health promotion from other allied health professions.

\section{Informing advocacy for health promotion}

Workshop participants indicated that they were regularly called upon to advocate for health promotion with their manager or employer within their organisation. The competencies were seen to be useful to explain the scope and relevance of health promotion to decision makers when advocating to secure health promotion budgets, or expand health promotion services. As managers often do not fully appreciate the scope of health promotion, the competencies could be a useful tool

Table 1: Health promotion workshops conducted throughout Australia in 2006.

\begin{tabular}{lccc}
\hline Date & State & Facilitators \\
\hline 26 July 2006 & Perth, WA & Trevor Shilton, Peter Howat, Ray James \\
16 August 2006 & Rural WA (VC) & Trevor Shilton, Ray James \\
11 September 2006 & Melbourne, Victoria & Cheryl Hutchins \\
20 September 2006 & Canberra, ACT & Cheryl Hutchins \\
19 September 2006 & Darwin, NT & Trevor Shilton \\
24 September 2006 & Sydney, NSW & Peter Howat \\
27 September 2006 & Brisbane, QLD & Peter Howat \\
9 October 2006 & Hobart, Tasmania & Ray James \\
10 October 2006 & Davenport, Rural Tasmania & Ray James \\
20 October 2006 & Adelaide, SA & Ray James \\
\hline Total & & 20 \\
\hline
\end{tabular}


in enabling the justification of health promotion programs and expenditures.

\section{Clarification of job roles}

A set of agreed health promotion competencies can provide everyone involved in health promotion activities with a more comprehensive understanding of the dimensions of the field. The 10 broad areas or categories and the 84 individual competencies that were confirmed by the 2006 revision process in Australia ${ }^{9}$ can be used to assist those professionals with formal university health promotion qualifications to match the competencies with the courses and unit of study they have completed. Similarly, the list can help provide clarification for newcomers to the field, or those who work in health promotion on an occasional basis. Competencies can help delineate roles and be used to write job descriptions for:

- designated health promotion workers;

- those for whom health promotion is only part of their role;

- individuals who perform specific or specialised roles within health promotion; and

- managers and other stakeholders.

Figure 1 depicts the health promotion workforce in nine quadrants, defined on the vertical axis by level of specialisation (specialist, generalist and the broader intersectoral workforce) and on the horizontal axis by level of seniority or experience (Manager, practitioner or graduate). Each of these groups has different needs and require variable competence to perform their health promotion roles. A future project might review the relevant core health promotion competencies required for each of these groups.

There is clearly a role for both specialists and generalists in the field of health promotion. Accordingly, there is nothing incongruent with the goal of assigning health promotion roles to a wide range of people in health and other sectors, while at the same time acknowledging a role for specialists.

Figure 1: Mapping the health promotion workforce.

\begin{tabular}{|c|c|c|c|}
\hline \multirow[b]{2}{*}{$\begin{array}{l}\text { Health } \\
\text { Promotion } \\
\text { Specialist }\end{array}$} & Manager & Practitioner & $\begin{array}{c}\text { Entry level } \\
\text { graduate }\end{array}$ \\
\hline & & & \\
\hline $\begin{array}{l}\text { Health } \\
\text { Promotion } \\
\text { Part of Role }\end{array}$ & & & \\
\hline $\begin{array}{l}\text { Broader } \\
\text { intersectoral } \\
\text { workforce }\end{array}$ & & & \\
\hline
\end{tabular}

\section{Personnel and human resource management uses of competencies for employers}

Competencies can assist health promotion employers, managers and supervisors in personnel management and human resources to improve the health promotion performance of staff and increase health promotion effectiveness in the workplace.

Human resource management uses include: definition of clear job role, establishing appropriate 'essential' or 'desirable' employment criteria, developing interview questions, designing matrices for ranking answers to questions and employment criteria, and guiding the establishment of priorities for the induction of new staff or entry level training.

Managers and policy makers may also use competencies for: performance management, guidelines for staff supervision, mentoring systems, facilitating organisational change in priorities and strategies, and informing policy outcomes.

\section{Building health promotion capacity in the health workforce}

Building health promotion capacity in the health workforce is a vital strategy for health gain. Health promotion competencies provide a framework for building capacity in health promotion organisations and individuals, other members of the health workforce, and in sectors such as transport, housing, local government and the environment. Competencies can be used to determine benchmarks for health promotion organisations and to set priorities for training activities such as: continuing education, workshops and seminars, induction programs, mentoring, secondments and exchange programs.

Building organisational capacity in the health workforce and in sectors other than health will contribute to increasing the number of people effectively promoting health. ${ }^{8}$

\section{Developing and revising tertiary education courses}

Health promotion competencies can be a useful tool for academics involved in providing education and training in health promotion in tertiary education..$^{3,12,13}$ Some of the uses include:

\section{Course development}

Competencies are useful for curriculum development of health promotion academic courses, especially three or four year bachelor degrees. Competencies can also be useful for identifying the health promotion components of postgraduate degrees such Master of Public Health programs that might only have a single core health promotion unit, or Masters of Health Promotion which might include several specific health promotion units. There will be more opportunity to include the full range of competencies in the undergraduate three or four-year program compared to the postgraduate courses 
which are typically constrained by a single year of course work. Consequently, this discussion will focus mainly on the use of competencies for undergraduate degrees.

Specifically, competencies can assist: the identification of overall course objectives; the identification of unit (subject) objectives or learning outcomes; the selection of content for individual units (subjects); and the development of evaluation processes of individual units. Examples include:

- Identification of overall course objectives. The set of health promotion competencies identified in the 2005/06 project includes broad, logical groupings (e.g.Needs and Determinants; Planning and Consultation; Community Empowerment). ${ }^{9}$ These groupings can provide an outline or direction for an academic course (e.g. A three-year health promotion bachelor degree) by informing or guiding the development of overall course objectives.

- Identification of unit (subject) objectives or learning outcomes. The specific competencies $(n=83)$ within 10 categories ${ }^{9}$ can be used to guide the development of the objectives or learning outcomes of the individual units or subjects (e.g. the three-year Bachelor degree at Curtin University has 24 units). ${ }^{12}$

- Selection of content for individual units (subjects). The unit objectives guide the content and learning activities that should be included within a particular unit. The course developers can ensure that there is alignment of the course content with these unit objectives.

- Development of evaluation processes of individual units (subjects). A unit evaluation typically consists of three assignments, projects or exams that students are required to complete for assessment. Completion of these assessment tasks should enable students to demonstrate the extent to which they have developed selected competencies. Students are more likely to understand the relevance of their studies and therefore will be more interested and motivated to learn if they are aware that the assessment tasks are directly based on or aligned to the unit objectives. This can benefit the student and the university and ultimately health promotion employers.

Such assessment also provides the unit teaching staff with feedback about how well the learning activities have assisted the student in developing those competencies.

\section{Course evaluation and revision}

A set of health promotion competencies can be used to assess existing health promotion academic courses. This process is probably more suitable for a three or four-year undergraduate course than for postgraduate courses. A process can be applied to identify the extent to which a health promotion course incorporates the main health promotion competencies via the overall course objectives, the individual unit (subject) objectives/learning outcomes, subject content, and unit assessment tasks. ${ }^{12}$ This process can also be utilised as part of a university's course quality control and review.

\section{To assist job seekers gain employment in health promotion}

To assist graduates gain employment

Graduates of health promotion courses often have difficulty constructing job applications and developing a resume. Health promotion competency lists can assist graduates to articulate the skills and knowledge that they have attained through course work, research and practicum placements. In addition, graduates may use the competencies to identify deficiencies in their skills. They can respond to this by professional development courses, volunteer work or additional studies to strengthen or enhance specific areas. ${ }^{14}$

To provide recognition of prior experience

Formal qualifications in health promotion are increasingly important in the job market. However, it is also acknowledged that adequate recognition should be given to relevant past experience, creativity and innovation. Health promotion is an eclectic and inclusive profession and dynamic in nature. Health promotion competencies provide an opportunity and a framework for assessing and recognising competencies and experience independent of formal qualifications. Practitioners can use the health promotion competencies language and structure to describe experience relevant to particular jobs.

\section{To provide a framework for credentialling in health promotion}

Competencies can provide a framework for commencing a process of credentialling for health promotion professionals. One essential pre-requisite for credentialling is the identification of a distinct discipline, with well-articulated, agreed content that is distinct from other professions. A system to recognise practitioner experience such as credentialling may lead to better consistency between States and organisations for remuneration of health promotion professionals and provide the way for more structured career paths within the profession. ${ }^{2,15}$ Nevertheless, there are a number of issues that are relevant to credentialling of health promotion professionals in Australia. ${ }^{13}$ These need careful consideration before such a system is introduced.

\section{Conclusions}

In recent years there has been significant progress in achieving consensus about agreed health promotion competencies in Australia. This work has instigated a dialogue in identifying 
the range of potential uses of these competencies. ${ }^{16}$ Agreed health promotion competencies can significantly impact on recruitment, training, employment policy and health promotion practice. Dialogue between experts, practitioners, trainers and employers can help to further articulate and implement the potential uses of these competencies. This has potential to advance professional practice in health promotion in Australia and other countries.

\section{References}

1. National Commission for Health Education Credentialing. A CompetencyBased Framework for Graduate-Level Health Educators. Whitehall (PA): NCHEC; 1999.

2. Gilmore GD, Olsen LK, Taub A, Connell D. Overview of the National Health Educator Competencies Update Project, 1998-2004. Health Educ Behav. 2005;32:725-37.

3. Hyndman B. Towards the Development of Canadian Health Promotion Competencies: Where We've Been, Where We Are, and Where We're Going. Toronto (CAN): Ontario Health Promotion E-Bulletin [homepage on the Internet]; 2007 October 25 [cited 25 April 2008]. Available from: http://www. ohpe.ca/ebulletin/index.php?option $=$ com_content\&task $=$ view\&id $=9068 \& \mathrm{It}$ emid $=78$

4. McCracken $\mathrm{H}$, Rance $\mathrm{H}$. Developing competencies for health promotion training in Aotearoa-New Zealand. Promotion and Education. 2000;7:40-43, 65.

5. Melville L, Howat P, Shilton T, Weinstein R. Competencies for health promotion practitioners in Israel. Promotion and Education. 2006;13(3):178-84.

6. Meresman S, Colomer-Revuelta C, Barry M, Davies JK, Lindstrom B, Loureiro $\mathrm{I}$, et al. A review of professional competencies in health promotion: European perspectives. International Journal of Health Promotion and Education. 2006;44:113-20.
7. Van Asselt K, Howat P, Henderson H, Shilton T, James R, et al. 1994. Identification of Competencies for the Health Promotion Practitioner: Phase 1. Proceedings of the 6th National Health Promotion Conference; 1994 February 13-15; Melbourne, Australia.

8. Shilton $\mathrm{T}$, Howat $\mathrm{P}$, James $\mathrm{R}$, Lower $\mathrm{T}$. Development of competencies for health promotion practitioners in Australia. Promotion and Education. 2003;10(4):162-71.

9. Shilton T, Howat P, James R, Burke L, Hutchins C, Woodman R. Health promotion competencies for Australia 2001-5: trends and their implications. Promotion and Education. 2008;15(2):21-6.

10. Hutchins $\mathrm{C}$, Shilton T, Howat P, Sann H, et al. International core competencies for health promotion: Is it possible to find consensus upon a set of core knowledge and skills for health promotion? Proceedings of the 18th IUHPE World Conference on Health Promotion and Health Education; 2004 April 26-30; Melbourne Australia.

11. Miles B, Huberman A. Qualitative Data Analysis: Data Management and Analysis Methods. Thousand Oaks (CA): Sage Publications; 1994.

12. Howat P, Maycock B, Jackson L, Lower T, Cross D, Collins J, et al. Development of competency based university health promotion courses. Promotion and Education. 2000;7(1):33-8.

13. Redman J, O'Hara L. Perception of credentialing for health promotion practitioners in Australia. Health Promot J Austr. 2003;14(1):25-31

14. Hazel F, Maycock B, Howat P. Development of an evidence guide for mapping health promotion competencies. ACHPER Healthy Lifestyles Journal. 2004;51(2):12-17.

15. Allegrante JP, Airhihenbuwa CO, Auld ME, Birch DA, Roe K, Smith BJ. Toward a unified system of accreditation for professional preparation in health education: Final Report of the National Task Force on Accreditation in Health Education. Health Educ Behav. 2004;31:668-83.

16. Shilton $T$, Howat $P$, James R, Hutchins $C$, Burke L. Uses of the Australian Health Promotion Competencies. Proceedings of the 19th IUHPE World Conference on Health Promotion and Health Education; 2007 June 10-15; Vancouver, Canada.

\section{Authors}

Trevor Shilton, National Heart Foundation of Australia (WA Division) and Western Australian Centre for Health Promotion Research, Curtin University

Peter Howat, Western Australian Centre for Health Promotion Research and Centre for Behavioural Research in Cancer Control, Curtin University, Western Australia

Ray James, Centre for Behavioural Research in Cancer Control, Curtin University, Western Australia

Cheryl Hutchins, Department of Health, Australian Capital Territory

Linda Burke, Western Australian Centre for Health Promotion Research and Centre for Behavioural Research in Cancer Control, Curtin University, Western Australia

Correspondence

Mr Trevor Shilton, Heart Foundation, 334 Rokeby Road, Subiaco, Western Australia 6008. Fax: (08) 9388 3383; e-mail: Trevor. Shilton@heartfoundation.com.au 